\title{
An evaluation of the clinical and cost-effectiveness of alternative care locations for critically ill adult patients with acute traumatic brain injury
}

R Grieve $\mathrm{PhD}^{1^{*}}, \mathrm{Z}$ Sadique PhD ${ }^{1}, \mathrm{M}$ Gomes $\mathrm{PhD}^{1}, \mathrm{M}$ Smith FRCA ${ }^{2}$, FE Lecky PhD ${ }^{3}$, PJA Hutchinson $\mathrm{PhD}^{4}$, DK Menon $\mathrm{PhD}^{4}$, KM Rowan $\mathrm{PhD}^{5}$, DA Harrison $\mathrm{PhD}^{5}$, on behalf of the Risk Adjustment In Neurocritical care (RAIN) Study Investigators

${ }^{1}$ Department of Health Services Research and Policy, London School of Hygiene and Tropical Medicine, London, United Kingdom, ${ }^{2}$ National Hospital for Neurology and Neurosurgery, University College London Hospitals NHS Foundation Trust, London, United Kingdom, ${ }^{3}$ School of Health and Related Research, University of Sheffield, Sheffield, United Kingdom, ${ }^{4}$ School of Clinical Medicine, University of Cambridge, Cambridge, United Kingdom, ${ }^{5}$ Clinical Trials Unit, Intensive Care National Audit and Research Centre, London, United Kingdom

*Corresponding author

Richard Grieve

Department of Health Services Research and Policy

London School of Hygiene \& Tropical Medicine

15-17 Tavistock Place, London WC1h 9SH

Tel: 0207927 2255, Fax: 02079272701

Email: Richard.Grieve@Ishtm.ac.uk

Key words: Cost-effectiveness analysis; traumatic brain injury; neurocritical care 


\section{Abstract}

Background: For critically ill adult patients with acute traumatic brain injury (TBI), we assessed the clinical and cost-effectiveness of:

a) Management in dedicated neurocritical care units versus combined neuro/general critical care units within neuroscience centres.

b) 'Early' transfer to a neuroscience centre versus 'no or late' transfer for those who present at a non-neuroscience centre.

Methods: The Risk Adjustment In Neurocritical care (RAIN) Study included prospective admissions following acute TBI to 67 UK adult critical care units during 2009-11. Data were collected on baseline case-mix, mortality, resource use, and at six months, Glasgow Outcome Scale Extended (GOSE), and quality of life (QOL) (EuroQol 5D-3L). We report incremental effectiveness, costs and cost per Quality-Adjusted Life Year (QALY) of the alternative care locations, adjusting for baseline differences with validated risk prediction models. We tested the robustness of results in sensitivity analyses. Findings: Dedicated neurocritical care unit patients $(\mathrm{N}=1,324)$ had similar six-month mortality, higher QOL (mean gain $0.048,95 \% \mathrm{Cl}-0.002$ to 0.099 ) and increased average costs compared with those managed in combined neuro/general units $(\mathrm{N}=1,341)$, with a lifetime cost per QALY gained of $£ 14,000$. 'Early' transfer to a neuroscience centre $(\mathrm{N}=584)$ was associated with lower mortality (odds ratio $0.52,0.34$ to 0.80 ), higher QOL for survivors (mean gain $0.13,0.032$ to 0.225 ), but positive incremental costs ( $f 15,001, f 11,123$ to $£ 18,880)$ compared with 'late or no transfer' $(\mathrm{N}=263)$. The lifetime cost per QALY gained for 'early' transfer was $£ 11,000$.

Conclusions: Within neuroscience centres, for critically ill adult patients with acute TBI, management in dedicated neurocritical care units is, on average, more cost-effective than in combined neuro/general units. This study finds that 'early' transfer to a neuroscience centre is associated with reduced mortality, improvement in QOL and is cost-effective. 


\section{Introduction}

Acute traumatic brain injury (TBI) is a major cause of death, and disability. ${ }^{1}$ The annual cost of acute TBI has been estimated at $\$ 60$ billion in the USA. ${ }^{2}$ For critically ill adult patients with acute TBI, access to specialist facilities, for example neuroscience centres, may differ across regions, but these variations are not informed by evidence of relative effectiveness or cost-effectiveness. ${ }^{3}$ Some evidence indicates that management of acute TBI in specialist neuroscience centres rather than nonneuroscience centres, may be associated with improved clinical outcomes. ${ }^{4,5}$ Several case series have suggested that dedicated clinical algorithms and protocols can improve mortality and functional outcomes following acute $\mathrm{TBI}^{6,}{ }^{6,7}$ but in the absence of RCTs, confounding is a key concern, and previous studies have not undertaken adequate risk-adjustment when comparing outcomes across settings, ${ }^{8}$ or considered relative costs.

In the UK NHS, the majority of acute TBI patients admitted to neuroscience centres are managed in neurocritical care units rather than combined neuro/general critical care units. However, the recent expansion of neurocritical care facilities is based on weak evidence of benefit from managing severe head injury in specialist centres. ${ }^{5}$ It is also unknown whether adult TBI patients without an acute 'neurosurgical' lesion benefit from 'early' transfer to a neuroscience centre; there may be a substantial risk of death from 'early' transfer and aggressive protocols of care in a neuroscience centre ${ }^{9,10} \mathrm{~A}$ competing concern, is that if the initial decision is not to transfer the patient to a neuroscience centre, critical lesions may develop subsequently; the patient may require a 'late' transfer at increased risk of an unfavourable outcome. ${ }^{11}$ While 'early' transfer to neuroscience centres has been recommended following acute TBI, the lack of evidence underpinning this guidance has been recognised by the National Institute for Health and Care Excellence (NICE), who listed this topic as a key area for further research. ${ }^{12}$ 
The Risk-Adjustment in Neurocritical Care (RAIN) Study aimed first, to validate risk prediction models following acute TBI in adult critical care units in the UK, and second to compare risk-adjusted outcomes and costs of alternative care locations following acute TBI. ${ }^{13}$

The objectives of this paper are to use the RAIN Study data to compare the effectiveness, costs, and cost-effectiveness of:

1. Management in a dedicated neurocritical care unit versus a combined neuro/general critical care unit;

2. 'Early' transfer to a neuroscience centre versus 'no or late' transfer, for patients who initially present at a non-neuroscience centre and do not require urgent neurosurgery.

\section{Methods}

\section{Overview}

This study compared the risk-adjusted outcomes, costs and lifetime cost-effectiveness of alternative care locations following acute TBI. Firstly, for patients admitted to neuroscience centres, we compared care within a dedicated neurocritical care unit (Figure 1a, panel A) versus within a combined neuro/general critical care unit (Figure 1a, panel B). Secondly, for patients who originally presented at a non-neuroscience centre, an 'early' transfer group was defined as those patients who transferred to a neuroscience centre, either directly from the emergency department, or from a critical care unit within 18 hours of initial hospital presentation (Figure $1 \mathrm{~b}$, panel A). The 'no or late' transfer group were defined as patients who received all their critical care within a nonneuroscience centre, and those who transferred to a neuroscience centre more than 24 hours after initial hospital presentation (Figure 1b, panel B). The cut-off times were chosen a priori by the clinical experts on the RAIN Study Steering Group. The definition of an 'early' transfer was intended to include all those patients where the initial decision was to transfer the patients, recognising local variations in the care pathway and logistical barriers to immediate transfer. Patients transferred 
between 18 and 24 hours, and those who underwent neurosurgery for evacuation of a mass lesion within 24 hours of initial hospital presentation, were excluded. Within the 'no or late' transfer group, $94 \%$ of patients were not transferred to a neuroscience centre. ${ }^{13}$

\section{Settings, patients and measurement of six month outcomes and costs}

The outcomes and costs of the alternative care locations were estimated from the RAIN Study. ${ }^{13}$ The RAIN Study recruited admissions following acute TBI to 67 adult critical care units in the UK during 2009-11. Each critical care unit was classified according to whether or not it was within a neuroscience centre, and if so, whether it was within a dedicated neurocritical care unit, or a combined neuro/general critical care unit. Within UK neuroscience centres, the RAIN Study included: all 13 centres with dedicated neurocritical care units, 14 ( $82 \%$ of the total) with combined neuro/general units and four additional units that did not meet either definition. The RAIN Study also included patients from $36(16 \%)$ general critical care units in non-neuroscience centres. All adult patients admitted to participating critical care units with a confirmed TBI and a last presedation Glasgow Coma Scale (GCS) of 3-14 were included. Detailed information was collected at the time of injury and at initial hospital presentation on age, sex, cause of injury, major extracranial injury, pupil reactivity, GCS, computed tomography (CT) characteristics (Marshall CT classification ${ }^{14}$ ). These baseline variables were used to predict the risks of death at six months according to the IMPACT Lab ${ }^{14}$ and CRASH CT ${ }^{15}$ risk prediction models. There two models were chosen following a review of published risk prediction models for critically ill adult patients with acute $\mathrm{TBI},{ }^{8,16}$ and were those found to perform best in external validation undertaken in the RAIN Study. ${ }^{13}$

\section{Six month outcomes}

For the index admission, information on vital status and the date of death were recorded on the RAIN Study Case Report Forms (CRFs). RAIN Study data were linked with death registration from the NHS information centre to give survival status and date of death for patients discharged from the 
initial hospital episode. At the six month follow-up, a postal questionnaire was administered to those patients known to be alive and eligible for follow-up. ${ }^{13}$ Patients (or their carers) were asked to complete the Glasgow Outcome Scale (Extended) (GOSE), and a generic health-related quality of life (QOL) questionnaire, the EuroQol 5-dimension, 3-level version (EQ-5D-3L). Unfavourable outcome at six months was measured as death or severe disability according to the GOSE. ${ }^{17}$ The EQ-5D-3L profiles were combined with health state preference values from the UK general population, ${ }^{18}$ to give EQ-5D-3L utility index scores on a scale anchored at 0 (death) and 1 (perfect health). QualityAdjusted Life Years (QALYs) were then reported by combining data on vital status and utility score at six months. Decedents were assigned zero QALYs.

\section{Resource use and costs}

The cost analysis took a health and personal social services perspective. The RAIN CRFs recorded length of stay (LOS) in critical care units and general medical wards from index admission and readmission. The CRFs also recorded whether or not the patient had intracranial neurosurgery for evacuation of a mass lesion. Each critical care bed-day was assigned to the appropriate Healthcare Resource Group (HRG) with daily organ support data recorded for the Critical Care Minimum Dataset (CCMDS) $\cdot{ }^{19}$ Data on other health and personal social service use (between discharge from the index hospital admission and six months follow-up) was collected from a service use questionnaire administered by post at the six month follow-up. ${ }^{13}$ Unit costs for resource use were taken from the 'Payment by Results' database ${ }^{20}$ and the literature (see Web supplement, Table S1). All unit costs were reported in 2010-11 prices.

\section{Analysis of six month costs and consequences}

Regression analysis used the IMPACT Lab mode ${ }^{14}$ which performed best in external validation in the RAIN Study. For mortality and unfavourable outcome at six months after the acute TBI, odds ratios were reported with logistic regression. For the comparisons of QOL, QALYs and cost at six months, 
we reported mean differences after adjustment with linear regression. For the first comparison we allowed for any clustering of patients within critical care units with multilevel models. For the second comparison, patients within each critical care unit could be in either comparison arm, we used single-level regression models for case-mix adjustment and to report pre-specified subgroup analyses according to age (70 years or less, or over 70 years), major extracranial injury (yes or no) and severity of TBI (GCS of 9-14, or 3-8). ${ }^{21}$ Missing data were addressed with multiple imputation assuming that data were 'missing at random', ${ }^{22}$ that is conditional on baseline covariates, resource use, and observed endpoints. We applied the analytical models to each imputed dataset $(n=25)$, and combined the resultant estimates with Rubin's rules. ${ }^{22}$

\section{Lifetime cost-effectiveness analysis}

We predicted patient-level lifetime costs and QALYs which required assumptions to be made about long-term survival, QOL and cost (see Web supplement for details, including Figures S1 and S2, and Tables S2-S4). We reported lifetime incremental costs, QALYs, and incremental cost-effectiveness ratios (ICERs). Incremental net monetary benefits (INBs) were estimated by valuing incremental QALYs at $£ 20,000$ per QALY, and subtracting from this the incremental costs. Cost-effectiveness acceptability curves (CEACs) were calculated by reporting the probability that each alternative was the most cost-effective (i.e. had a positive INB) at different ceiling ratios of willingness to pay for a QALY gain. Lifetime costs and QALYs were discounted at 3.5\%. We undertook sensitivity analyses to assess whether the cost-effectiveness results were robust to alternative assumptions. The base case assumptions and sensitivity analyses undertaken were as follows:

(a) In the base case analysis, for those surviving six months after hospital presentation, subsequent death rates were assumed to be the the same as for the age-gender matched general population. ${ }^{13,23}$ In this sensitivity analysis, lifetime mortality was estimated by applying the parametric function judged the most plausible (Gompertz) to the observed data. ${ }^{24}$ 
(b) The base case assumed that QOL at 10 years post acute TBI was $5 \%$ lower than for the agegender matched general population. ${ }^{25}$ In the sensitivity analysis, we instead assumed that the decrement in QOL reported in the RAIN Study at six months versus the general population, was maintained over the patients' lifetime.

(c) The costs considered from six months after the acute TBI were those from readmissions to general medical wards, and from use of outpatient and community services. In the base case analysis these costs were applied for three years, after which no further costs were assumed to be attributable to the acute TBI. The sensitivity analyses considered (i) readmission costs to general medical wards for five years; and (ii) outpatient and community costs for upto 10 years.

(d) In the base case analysis, the unit costs of critical care were allowed to differ across clinical centres, according to the variations observed in the Payment by Results database. In the sensitivity analysis, the same unit costs were assumed across care locations.

(e) The base case analysis assumed QOL data from the RAIN Study applied to the six month timepoint, irrespective of the time at which the QOL questionnaire was completed. In the sensitivity analysis, we assumed that patients whose follow-up was before 150 or after 220 days, had missing QOL data, and used multiple imputation to impute their six month QOL data.

(f) We assumed that costs followed a Normal distribution in the base case analysis, whereas the sensitivity aanalysis assumed they followed a Gamma distribution.

(g) Risk equations from the IMPACT LAB model were applied in the base case analysis, and from the CRASH CT mode ${ }^{15}$ in the sensitivity analysis.

(h) 'Early' transfer to a neuroscience centre was defined as within 18 hours of hospital presentation in the base case and within eight hours of hospital presentation in the sensitivity analysis.

(i) In the base case, the second comparison included all patients irrespective of their pupil reactivity. In the sensitivity analysis, patients with neither pupil reactive were excluded. 


\section{Results}

\section{Baseline characteristics}

For the patients with acute TBI admitted directly to neuroscience centres, baseline characteristics were similar between those admitted to dedicated neurocritical care units, versus combined neuro/general critical care units (Table 1). For patients admitted to non-neuroscience centres the 'early' transfer group were on average younger and less severely ill than the 'no or late' transfer group. The 'no or late' transfer group had a higher proportion of patients with a GCS of 3-8, unreactive pupils, and a Marshall CT classification indicating non-evacuated mass lesion. The median predicted risk of death at six months was higher for the 'no or late' transfer group compared with the 'early' transfer group.

\section{Six month outcomes}

The proportion of patients who died before six months was similar following care in a dedicated neurocritical care unit versus those in a combined neuro/general critical care unit (Table 2a). The dedicated neurocritical care unit group had a higher mean EQ-5D-3L utility index score for survivors, a lower proportion of patients with unfavourable outcomes and higher mean QALYs, but none of these differences was statistically significant, after case-mix adjustment. A lower proportion of patients died before six months in the 'early' versus the 'no or late' transfer group (adjusted odds ratio $0.52,95 \% \mathrm{Cl} 0.34$ to 0.80 ; Table $2 \mathrm{~b}$ ). The 'early' transfer group reported higher mean EQ-5D-3L utility index score for survivors, and higher average QALYs.

The subgroup of patients aged over $70(n=86)$ had a higher odds of death in the 'early' versus the 'no or late' transfer group, but the Cls around the odds ratio were wide and included 1 (Web supplement Table S5). For the other subgroups, a higher proportion of patients died in the 'no or late' versus the 'early' transfer group. 


\section{Resource use and cost up to six months}

The dedicated neurocritical care unit group had a higher average LOS in critical care than the combined neuro/general critical care unit group, (Table 3a), which led to positive incremental costs at six months of approximately $£ 3,700$. For the 'early' transfer group the average LOS in critical care, on general wards and in total, was approximately double that of the 'no or late' transfer group (Table 3b). A higher proportion of patients in the 'early' transfer group had an intracranial procedure for evacuation of a mass lesion, at least 24 hours after initial presentation. The 'early' transfer group, had a positive incremental cost overall $(£ 15,000)$, and for each subgroup (Web supplement, Table S5).

\section{Lifetime CEA}

Critically ill adult patients with acute TBI admitted to neuroscience centres and managed in dedicated neurocritical care units rather than combined neuro/general critical care units, had higher average lifetime QALYs, at a small additional mean cost; the ICER was around $£ 14,000$ per QALY (Table 4a). At a ceiling ratio of $£ 20,000$ per QALY, the INB was positive $(£ 1,300)$. The probability that dedicated versus combined neurocritical care units are cost-effective, is around $60 \%$ at realistic threshold willingness to pay for a QALY gain (Web supplement Figure S3a). For the patients admitted to non-neuroscience centres following acute TBI, the average lifetime QALYs and costs were both higher for the 'early' transfer group than the 'no or late' transfer group. The ICER was approximately $£ 11,000$ per QALY (Table $4 \mathrm{~b}$ ). The corresponding probability that 'early transfer' to a neuroscience centre is cost-effective is almost $100 \%$ (Web supplement Figure S3b).

The sensitivity analyses find that the base case findings are robust to most alternative approaches taken (Figure 2a and b). The exception is that if the second comparison excludes patients with neither pupil reactive, the effect of early transfer on six month mortality is reduced (adjusted odds 
ratio $0.856,95 \% \mathrm{Cl} 0.518$ to 1.416 ), and the corresponding INB for 'early' transfer is negative with a $95 \% \mathrm{Cl}$ that includes zero (Figure $2 \mathrm{~b}$ ).

The subgroup analysis reported that 'early' transfer was highly cost-effective for patients aged 70 or less ( $n=761$ ), but was not cost-effective for those aged over 70 ( $n=86)$, (Web supplement Figure S4a). For all other subgroups, 'early' transfer was more cost effective than 'no or late' transfer (Web supplement Figures S4b and S4c). 


\section{Discussion}

This paper finds that for critically ill patients with acute TBI who present at a neuroscience centre, average QOL after six months is higher following care in dedicated neurocritical care units than combined neuro/general units. However, this difference is not statistically significant and dedicated critical care units have higher critical care costs. For critically ill adult patients who present at a nonneuroscience centre and do not require immediate neurosurgery following acute TBI, 'early' transfer to a neuroscience centre is associated with lower mortality after six months, and survivors have higher average QOL. The 'early' transfer group also has higher average total costs which reflect the increased survival, but the lifetime QALY gains are sufficient to justify the additional costs, and so 'early' transfer is cost-effective. This finding applies to all subgroups apart from for older patients (aged over 70). While the sensitivity analysis reports the results are generally robust to alternative assumptions, it does report that the 'early transfer' policy is no longer more effective or costeffective once patients with neither pupil reactive are excluded. The 'late or no' transfer group had a higher proportion of patients with neither pupil reactive, and may therefore include a higher proportion of patients with unmeasured characteristics associated with increased mortality. Hence, any recommendation that critically ill patients with acute TBI should be transferred 'early' to neuroscience centres, has to recognise the potential for unobserved confounding.

This paper extends the previous literature on the relative effectiveness of alternative locations of neurocritical care. ${ }^{26-28}$ This paper is the first to evaluate the cost-effectiveness of alternative care locations following acute TBI, and uses established risk prediction models, subject to a rigorous validation study in critically-ill adults with acute TBI. The finding that average risk-adjusted QOL is higher if acute TBI patients are managed in dedicated neurocritical care units, rather than a combined neuro/general critical care unit has several possible explanations. First, a dedicated multidisciplinary team may provide more effective, immediate acute rehabilitation, and improve access to specialised neuro rehabilitation after discharge from the critical care unit. ${ }^{29}$ Second, 
dedicated units may offer more aggressive monitoring and management, which can reduce morbidity, ${ }^{5}$ and the RAIN Study finds this did not increase six-month mortality. Third, the dedicated neurocritical care units may have less severe case-mix according to unmeasured variables. Finally, the difference in the mean QOL between the settings may simply reflect chance variation as the differences was not statistically significant.

The finding that 'early' transfer to a neuroscience centre following acute TBI patients is costeffective is driven by the gains in survival and QOL observed at six months after hospital presentation. For non-surgical patients, previous research suggested that early transfer and more aggressive management may lead to increased risks that outweigh any gains, ${ }^{30}$ whereas other studies report that delayed transfer may lead to worse outcomes. ${ }^{11}$ In the RAIN Study, only a small proportion (6\%) of the 'no or late' transfer group had a delayed transfer, and so the main contrast is between a decision to transfer the TBI patient to a neuroscience centre 'early', versus continued management at a non-neuroscience centre. Previous evidence suggests benefits from early transfer for patients presenting with a space occupying haematoma with worsening mass effect, but the RAIN Study excludes patients who required neurosurgery within 24 hours, and therefore extends the evidence on the effectiveness of early transfer, to other critically ill patients with TBI. Here, while around one third of patients in both comparison groups presented with a mass lesion, only one patient in the 'no or late' transfer group had neurosurgery after 24 hours, compared to $48(8 \%)$ of patients in the 'early' transfer group.

The definition of an 'early' transfer is arbitrary, and may differ across contexts. A potential concern is that the effectiveness of an 'early' transfer policy could be highly sensitive to the cut-off point, and previous evidence from trauma networks encourages a four hour time window for neurosurgical interventions. ${ }^{3}$ Our sensitivity analysis suggests that applying an eight rather than an 18 hour time 
window from hospital presentation does not have large impact on the effectiveness or the costeffectiveness of the 'early' transfer policy.

This study has some limitations. First, the RAIN Study only measured costs and outcomes for up to six months. The lifetime CEA made assumptions when extrapolating from these data, but the sensitivity analyses suggested the results were robust to alternative extrapolation methods. Second, some follow-up data were missing for the six month endpoints, which we addressed with multiple imputation approaches. Third, in any non-randomised comparison the major concern is residual confounding. We allowed for baseline differences between the comparison arms with the published risk prediction model that performed best in external validation, ${ }^{14}$ and the sensitivity analysis suggested the results were similar when an alternative risk adjustment method was used. However, the results could be explained by differences between the comparison groups in prognostic factors that were not in the published risk models, nor measured in the RAIN Study. For example, in the RAIN Study the definition of major extracranial injury was broad and did not recognise the injury's severity. Further research would ideally record and adjust for potential confounders beyond those measured in the RAIN Study.

\section{Conclusions}

This paper finds that for critically ill adult patients with acute TBI who present at, or are transferred to, a neuroscience centre, management in a dedicated neurocritical care unit rather than a combined neuro/general critical care unit is associated with small gains in average QOL, at low additional costs, although these differences were not statistically significant. For adult patients with acute TBI who present at a non-neuroscience centre and do not require neurosurgery within 24 hours, 'early' transfer is more cost-effective than 'no or late' transfer to a neuroscience centre, after risk adjustment. 


\section{Author's contribution}

Dr Richard Grieve (Professor of Health Economics Methodology) designed the economic evaluation, contributed to the analysis and interpretation of the data, drafted and critically reviewed the manuscript.

Dr Zia Sadique (Lecturer, Health Economics) contributed to the analysis and interpretation of the data and drafted the manuscript.

Dr Manuel Gomes (Research Fellow, Health Economics) contributed to the analysis and interpretation of the data, and drafted the manuscript.

Professor Martin Smith (Consultant and Honorary Professor in Neuroanaesthesia and Neurocritical Care) conceived and designed the study, contributed to the acquisition and interpretation of the data and critically reviewed the manuscript.

Professor Fiona Lecky (Clinical Professor in Emergency Medicine and Research Director of TARN) contributed to the design of the study, interpretation of the data, and critically reviewed the manuscript.

Professor Peter Hutchinson (NIHR Research Professor and Honorary Consultant Neurosurgeon) contributed to the design of the study, acquisition and interpretation of the data, and critically reviewed the manuscript.

Professor David Menon (Professor of Anaesthesia and Consultant, Neurosciences Critical Care, and Research Lead for NCCNet) conceived and designed the study, contributed to the acquisition and interpretation of the data and drafted and critically reviewed the manuscript.

Professor Kathryn Rowan (Director of ICNARC and Honorary Professor of Health Services Research) conceived and designed the study, contributed to acquisition, analysis and interpretation of the data, and critically revised the manuscript.

Dr David Harrison (Senior Statistician) designed the study, contributed to the analysis and interpretation of the data and drafted and critically reviewed the manuscript. 


\section{Declaration of interests}

DKM is a paid consultant or member of a Data Monitoring Committee for Solvay Ltd, GlaxoSmithKline Ltd, Brainscope Ltd, Ornim Medical, Shire Medical and Neurovive Ltd. His institution receives payment for a registered patent for a new positron emission tomography ligand assessing mitochondrial function. The other authors report no conflicts of interest.

\section{Funding}

National Institute for Health Research Health Technology Assessment (NIHR HTA) Programme (07/37/29)

\section{Acknowledgements}

We acknowledge the contributions of all involved with the RAIN Study including RAIN Study Management Group, RAIN Study Steering Group, and research staff at participating sites. We wish to thank all the participants for taking part in the study, GPs and health care professionals for their assistance in patient follow-up, the Scottish Intensive Care Society Audit Group for providing access to their database, and the Trauma Audit and Research Network for providing data for verification of recruitment. We wish to thank the Neurocritical Care Network for adopting and supporting the Study.

\section{RAIN Study Investigators}

Dr David Harrison (Chief Investigator); Dr Richard Grieve; Professor Peter Hutchinson; Professor Fiona Lecky; Professor David Menon; Professor Kathy Rowan; Professor Martin Smith; Dr Paddy Yeoman.

\section{RAIN Study Management Group}

Dr Gita Prabhu (Study Coordinator); Andrew Craven (previous Research Administrator); Kathryn Griggs (Statistical Research Assistant); Dr David Harrison (Chief Investigator); Dr Sheila Harvey (CTU Manager/Senior Research Fellow); Phil Restarick (previous Research Coordinator); Professor Kathy 
Rowan (Co-investigator); Andrew Stenson (previous Research Manager); Emma Walmsley (Research Assistant).

\section{RAIN Study Steering Group}

Professor Monty Mythen (Independent chair); Julie Bridgewater (Independent); Dr Richard Grieve; Dr David Harrison; Professor Peter Hutchinson; Mr Jonathan Hyam (Independent); Professor Fiona Lecky; Professor David Menon; Professor Kathy Rowan; Professor Martin Smith; Dr lan Tweedie (Independent); Dr Paddy Yeoman.

\section{RAIN Study Research Team}

D Menon, L Moore, J Outtrim (Addenbrooke's Hospital); H Black, R Jacob, C Smalley (Arrowe Park Hospital); S Chau, A Bowry, C Denniss, D Raw, M Reid (Barnsley District Hospital); M Sun Wai, E Bilton, H Chitty (Basildon Hospital); J Cupitt, S Baddeley (Blackpool Victoria Hospital); R Meacher, M Templeton (Charing Cross Hospital); R Wroth, A Jarvis, J Toms (Chesterfield Royal Hospital); J Bleasdale, J Edwards, A McCann (City Hospital and Sandwell General Hospital); N Robin, H Jeffrey (Countess of Chester Hospital); V Prasad, P Wakefield (Darent Valley Hospital); E Thomas, H McMillan, T Quintrell (Derriford Hospital); A Asumang, M Wain (Diana, Princess of Wales Hospital); A Manara, S Grier (Frenchay Hospital); A Gratrix, N Smith (Hull Royal Infirmary); I Littlejohn, J Powell, G Spurling (Hurstwood Park Neurological Centre); H Madder, J Smith, J Titchell (John Radcliffe Hospital); P Hopkins, J Dawson, D Hadfield (King's College Hospital); D Holden, M Coggon, S Fleming (King's Mill Hospital); J Adams, Z Beardow, S Elliot (Leeds General Infirmary); N Flint, K Clarkson, A Smith (Leicester Royal Infirmary); D Simpson, N Pinto (Medway Maritime Hospital); H Jones (Morriston Hospital); M Smith, B Boyd, H Burgess, F Chong (National Hospital for Neurology and Neurosurgery); S Edwards, C Hughes (Nevill Hall Hospital); S Fletcher, M Rosbergen (Norfolk and Norwich University Hospital); A Walder, K Jones (North Devon District Hospital); J Cuesta, M Dlamini (North Middlesex University Hospital); J Wilkinson, R Marsh, K Brough (Northampton General Hospital); T Gallacher, M Lycett, T Matthews, T Thornhill (Queen Elizabeth Hospital Birmingham and Selly Oak Hospital); R Jain, K Reid (Queen's Hospital, Romford and Royal Berkshire Hospital); P 
Yeoman, A Jarvis, J Litchfield, H Wright (Queen's Medical Centre); S Thornton (Royal Bolton Hospital); J Paddle, K Burt (Royal Cornwall Hospital); J Andrzejowski, A Pritchard, K Bouakline (Royal Hallamshire Hospital); A Vincent, C Higham, P Laws, H McConnell (Royal Victoria Infirmary previously Newcastle General Hospital); R Protheroe (Salford Royal Hospital); R Sharawi, A Day (Scunthorpe General Hospital); R Lightfoot, K Linford, J Mitchell, R Oram, S Tollerfield (Southampton General Hospital); D Higgins, S Andrews (Southend University Hospital); SP Young, L Stewart (Southern General Hospital); P Razis, V Frazer (St George's Hospital); M Watters, K Challis, K Mayell (The Great Western Hospital); R Lewis, S Bell, A Kong (The Ipswich Hospital); J Wright, K Hugill (The James Cook University Hospital); K Blenk, L Everett (The James Paget Hospital); D Dutta, C McClements, J Power (The Princess Alexandra Hospital); A Guha, J Nolan, A Walker, K Williams (The Royal Liverpool University Hospital); V Verma, K Maitland, G Marshall (The Royal London Hospital); D Watson, J Bradshaw, K Flahive, R Jackson, G Ward (University Hospital Coventry); M Mostert, V Todman (University Hospital Lewisham); V Gupta (University Hospital of Hartlepool and University Hospital of North Tees); S Krueper, R Ahern, D Cartlidge (University Hospital of North Staffordshire); G Scholey, S Fernandez, N Haskins, S Shah, A Williams (University Hospital of Wales); C Whitehead, J Cater, D Davies, C Owen, D Watling (Walton Centre for Neurology \& Neurosurgery); J Cardy, S Humphreys, C Swanevelder (West Suffolk Hospital); P Andrews, E Grant (Western General Hospital); F Keane, I Bird (Whipps Cross University Hospital); C Jones, S Dowling, A McCairn (Whiston Hospital); D Southern, V Cunningham, C Hirst (Wrexham Maelor Hospital). 
Figure Legends

Figure 1(a). Comparators for research objective 1: alternative care locations within neuroscience centres

Figure 1(b). Comparators for research objective 2: 'early' versus 'no or late' transfer to a neuroscience centre

Figure 2(a). Sensitivity analyses reporting mean ( $95 \%$ confidence intervals) incremental net monetary benefit (INB) comparing care for dedicated neurocritical care units versus combined neuro and general critical care units

Figure 2(b). Sensitivity analyses reporting mean (95\% confidence intervals) incremental net monetary benefit (INB) comparing 'early' versus 'no or late' transfer to a neuroscience centre 


\section{References}

1. McMillan TM, Teasdale GM, Weir CJ, Stewart E. Death after head injury: the 13 year outcome of a case control study. J NeurolNeurosurgPsychiatry 2011;82(8):931-5

2. Centers for Disease Control and Prevention. Traumatic Brain Injury in the United States. Emergency Department visits, hospitalizations and deaths 2002-2006. Washington: US Department of Health and Human Services; 2010.

3. Barratt $\mathrm{H}$, Wilson $\mathrm{M}$, Moore $\mathrm{F}$, Raine $\mathrm{R}$. The implications of the NICE guidelines on neurosurgical management for all severe head injuries: systematic review. EmergMed J $2010 ; 27(3): 173-8$

4. Fuller G, Bouamra O, Woodford M, Jenks T, Patel H, Coats TJ, et al. The effect of specialist neurosciences care on outcome in adult severe head injury: a cohort study. J NeurosurgAnesthesiol 2011;23(3):198-205

5. Patel HC, Bouamra O, Woodford M, King AT, Yates DW, Lecky FE. Trends in head injury outcome from 1989 to 2003 and the effect of neurosurgical care: an observational study. Lancet 2005;366(9496):1538-44

6. Bulger EM, Nathens AB, Rivara FP, Moore M, MacKenzie EJ, Jurkovich GJ. Management of severe head injury: institutional variations in care and effect on outcome. Crit Care Med 2002;30(8):1870-6

7. Elf K, Nilsson P, Enblad P. Outcome after traumatic brain injury improved by an organized secondary insult program and standardized neurointensive care. Crit Care Med 2002;30(9):2129-34

8. Perel P, Edwards P, Wentz R, Roberts I. Systematic review of prognostic models in traumatic brain injury. BMCMed InformDecisMak 2006;6:38

9. Andrews PJ, Piper IR, Dearden NM, Miller JD. Secondary insults during intrahospital transport of head-injured patients. Lancet 1990;335(8685):327-30 
10. Gentleman D, Jennett B. Hazards of inter-hospital transfer of comatose head-injured patients. Lancet 1981;2(8251):853-4

11. Badjatia N, Carney N, Crocco TJ, Fallat ME, Hennes HM, Jagoda AS, et al. Guidelines for prehospital management of traumatic brain injury 2nd edition. PrehospEmergCare 2008;12 Suppl $1: \$ 1-52$

12. National Collaborating Centre for Acute Care. Head injury: Triage, assessment, investigation and early management of head injury in infants, children and adults. London: National Institute for Health and Clinical Excellence; 2007.

13. Harrison D, Prabhu G, Grieve R, Harvey SE, Sadique MZ, Gomes M, et al. Risk Adjustment In Neurocritical care (RAIN): prospective validation of risk prediction models for adult patients with acute traumatic brain injury to use to evaluate the optimum location and comparative costs of neurocritical care. Health Technology Assess 2013 17(23):vii-viii: 1-350

14. Steyerberg EW, Mushkudiani N, Perel P, Butcher I, Lu J, McHugh GS, et al. Predicting outcome after traumatic brain injury: development and international validation of prognostic scores based on admission characteristics. PLoS Med 2008;5(8):e165

15. MRC Crash Trial Collaborators. Predicting outcome after traumatic brain injury: practical prognostic models based on large cohort of international patients. BMJ 2008;336(7641):425-9

16. Griggs KA, Prabhu G, Gomes M, Lecky FE, Menon DK, Rowan KM, et al. External validation of risk prediction models for acute traumatic brain injury among critically ill adult patients: cohort study. Journal of Neurotrauma (under review) 2014

17. Teasdale GM, Pettigrew LE, Wilson JT, Murray G, Jennett B. Analyzing outcome of treatment of severe head injury: a review and update on advancing the use of the Glasgow Outcome Scale. J Neurotrauma 1998;15(8):587-97

18. Dolan P, Gudex C, Kind P, Williams A. A Social Tariff for EuroQoL: Results from a UK General Population Survey. CHE Discussion Paper 138. York: Centre for Health Economics, University of York; 1999. 
19. NHS Information Standards Board. Paediatric Critical Care Minimum Data Set. London2007.

20. Department of Health. NHS reference costs 2010-2011. London: Department of Health; 2011.

21. Andriessen TM, Horn J, Franschman G, van der NJ, Haitsma I, Jacobs B, et al. Epidemiology, severity classification, and outcome of moderate and severe traumatic brain injury: a prospective multicenter study. J Neurotrauma 2011;28(10):2019-31

22. Rubin DB. Multiple Imputation for Nonresponse in Surveys. New York: J Wiley \& Sons; 1987.

23. Office for National S. Interim Life Tables, 2008-2010. Newport: Office for National Statistics; 2011.

24. Latimer N. Survival analysis for economic evaluations alongside clinical trials - extrapolation with patient-level data. NICE DSU technical support documents: No. 14. Sheffield: University of Sheffield; 2011.

25. Jacobsson LJ, Westerberg M, Lexell J. Health-related quality-of-life and life satisfaction 6-15 years after traumatic brain injuries in northern Sweden. Brain Inj 2010;24(9):1075-86

26. Faul M, Wald MM, Rutland-Brown W, Sullivent EE, Sattin RW. Using a cost-benefit analysis to estimate outcomes of a clinical treatment guideline: testing theBrain Trauma Foundation guidelines for the treatment of severe traumatic brain injury. J Trauma 2007;63(6):1271-8

27. Ibrahim MI, Abdullah M, Naing L, Abdullah JM, Idris Z, Aljunid SM. Cost effectiveness analysis of using multiple neuromodalities in treating severe traumatic brain injury in a developing country like Malaysia. Asian J Surg 2007;30(4):261-6

28. Park CA, McGwin G, Jr., Smith DR, May AK, Melton SM, Taylor AJ, et al. Trauma-specific intensive care units can be cost effective and contribute to reduced hospital length of stay. AmSurg 2001;67(7):665-70

29. Teig M, Smith M. Where should patients with severe traumatic brain injury be managed? All patient should be managed in a neurocritical care unit. J NeurosurgAnesthesiol 2010;22(4):357-9 
30. Cremer OL, van Dijk GW, van Wensen E, Brekelmans GJ, Moons KG, Leenen LP, et al. Effect of intracranial pressure monitoring and targeted intensive care on functional outcome after severe head injury. Crit Care Med 2005;33(10):2207-13 


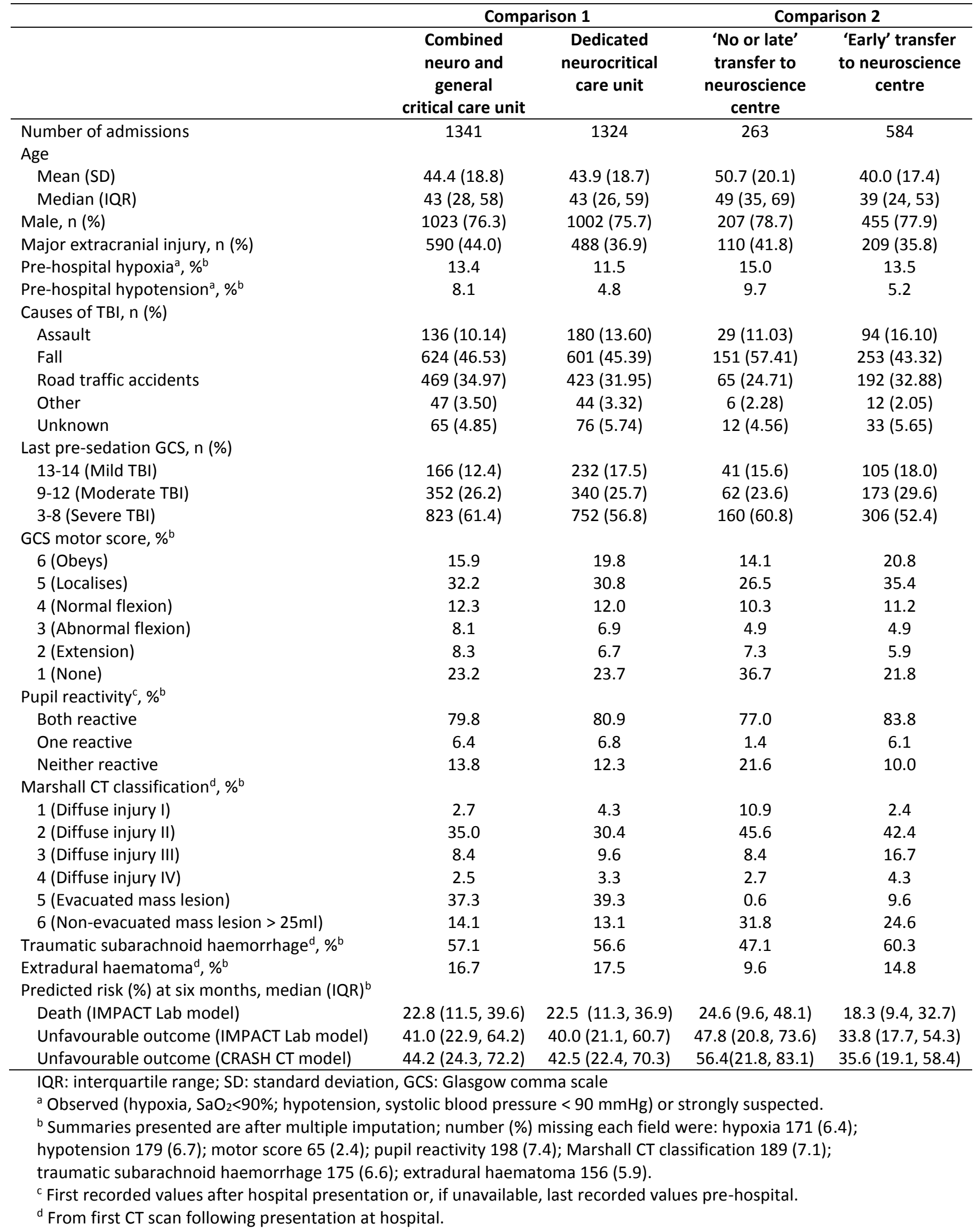


Table 2. Mortality, EuroQol 5-dimension (EQ-5D), unfavourable outcome and quality-adjusted life years

(QALY) at six months following acute TBI

(a) Comparison 1: dedicated neurocritical care unit versus combined neuro and general critical care unit ${ }^{*}$

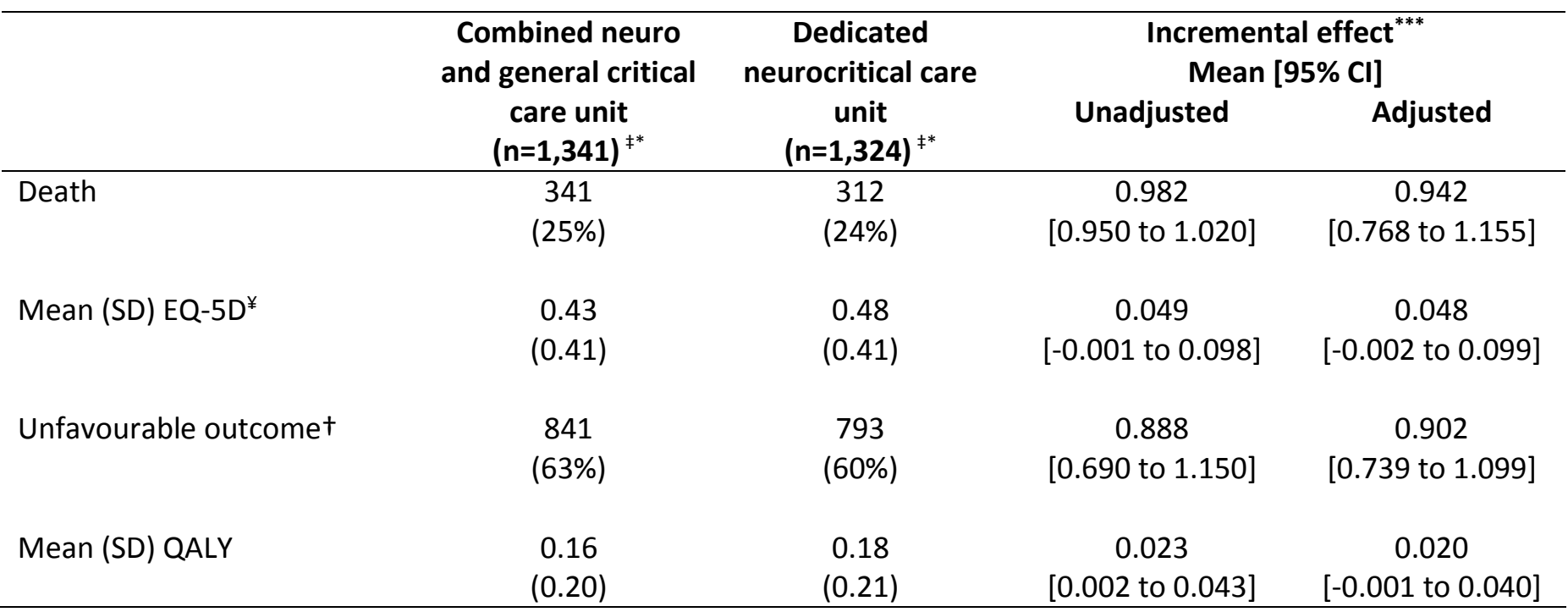

(b) Comparison 2: 'Early' versus 'no or late' transfer to a neuroscience centre ${ }^{* *}$

\begin{tabular}{|c|c|c|c|c|}
\hline & \multirow{2}{*}{$\begin{array}{c}\text { 'No or late' } \\
\text { transfer to } \\
\text { neuroscience } \\
\text { centre } \\
(n=263)^{\neq * *}\end{array}$} & \multirow{2}{*}{$\begin{array}{c}\text { 'Early' transfer to } \\
\text { neuroscience } \\
\text { centre } \\
(n=584)^{\ddagger * *}\end{array}$} & \multicolumn{2}{|c|}{$\begin{array}{c}\text { Incremental effect } \\
\text { Mean }[95 \% \mathrm{Cl}]\end{array}$} \\
\hline & & & Unadjusted & Adjusted \\
\hline Death & $\begin{array}{c}107 \\
(41 \%)\end{array}$ & $\begin{array}{c}109 \\
(19 \%)\end{array}$ & $\begin{array}{c}0.334 \\
{[0.242 \text { to } 0.462]}\end{array}$ & $\begin{array}{c}0.521 \\
{[0.338,0.803]}\end{array}$ \\
\hline Mean (SD) EQ-5D & $\begin{array}{c}0.44 \\
(0.37)\end{array}$ & $\begin{array}{c}0.55 \\
(0.41)\end{array}$ & $\begin{array}{c}0.108 \\
{[0.011 \text { to } 0.205]}\end{array}$ & $\begin{array}{c}0.129 \\
{[0.032,0.225]}\end{array}$ \\
\hline Unfavourable outcome ${ }^{\dagger}$ & $\begin{array}{c}169 \\
(65 \%)\end{array}$ & $\begin{array}{c}307 \\
(53 \%)\end{array}$ & $\begin{array}{c}0.609 \\
{[0.173 \text { to } 2.150]}\end{array}$ & $\begin{array}{c}0.884 \\
{[0.280,2.787]}\end{array}$ \\
\hline Mean (SD) QALY & $\begin{array}{c}0.13 \\
(0.18)\end{array}$ & $\begin{array}{c}0.22 \\
(0.21)\end{array}$ & $\begin{array}{c}0.093 \\
{[0.056 \text { to } 0.130]}\end{array}$ & $\begin{array}{c}0.051 \\
{[0.015,0.086]}\end{array}$ \\
\hline
\end{tabular}

GOSE: Glasgow Outcome Scale (Extended); Cl: confidence interval; SD: standard deviation

${ }^{*}$ The response rates to six month questionnaires were similar across comparison groups. Response rate for GOSE and EQ-5D ( 3 level version) questionnaire in comparison 1 were $80 \%$ ( $77 \%$ in combined arm versus $82 \%$ in dedicated arm) \& $50 \%$ (49\% in combined arm versus $52 \%$ in dedicated arm) respectively.

${ }^{* *}$ Response rate for GOSE and EQ-5D (3 level version) questionnaire in comparison 2 were $79 \%$ (75\% in 'no or late transfer' arm versus $80 \%$ in early transfer arm) and $50 \%$ (46\% in 'no or late transfer' arm versus $51 \%$ in 'early transfer' arm) respectively.

${ }^{* * *}$ Odds ratio for death and unfavourable outcome; incremental for other estimates. 
${ }^{\ddagger}$ Results reported as $\mathrm{n}(\%)$ if not stated otherwise

${ }^{*}$ Results reported for survivors

+ Death or severe disability 
Table 3. Hospital resource use and costs ( $\mathrm{f}$ ) up to six months after acute TBI

(a) Comparison 1: dedicated neurocritical care unit versus combined neuro and general critical care unit

$\begin{array}{ccc}\begin{array}{c}\text { Combined neuro and } \\ \text { general }\end{array} & \begin{array}{c}\text { Dedicated } \\ \text { neurocritical }\end{array} & \begin{array}{c}\text { Incremental cost } \\ \text { ( }\end{array} \\ \begin{array}{c}\text { critical care unit } \\ (n=1,341)\end{array} & \text { care unit }^{\ddagger} & \\ (n=1,324) & \end{array}$

(a1) Resource use

Index admission ${ }^{\mathrm{a}}$

Days in critical care

Days on general medical wards

$\begin{array}{cc}11.08(10.83) & 13.19(15.07) \\ 26.26(36.03) & 24.69(33.96) \\ 37.34(40.49) & 37.89(39.62) \\ 477(35.57) & 478(36.10) \\ 66(4.92) & 100(7.55) \\ 0.68(5.24) & 0.80(5.05) \\ 38.02(41.27) & 38.69(40.49)\end{array}$

Total hospital days - index admission

Neuro-surgery ${ }^{* *}, \mathrm{n}(\%)$

$\mathrm{n}(\%)$ readmission

Total hospital days -readmission ${ }^{a, b}$

Total hospital days up to six months $s^{a, b}$

$38.02(41.27)$

38.69 (40.49)

\section{(a2) Costs}

Index admission ${ }^{a}$

Critical care costs

$\begin{array}{cc}16,685(15,355) & 20,274(21,773) \\ 6,631(9,122) & 6,233(8,592) \\ 1,374(4,970) & 1,566(4,869) \\ 777(1,939) & 782(1,932) \\ 25,466(21,468) & 28,855(25,970)\end{array}$

$3,694[1,899$ to 5,489$]$

(b) Comparison 2: 'early' versus 'no or late' transfer to a neuroscience centre

$\begin{array}{ccc}\begin{array}{c}\text { 'No or late' transfer to } \\ \text { neuroscience centre }\end{array} & \begin{array}{c}\text { 'Early' transfer } \\ \text { to neuroscience } \\ \text { centre } \\ (n=584)\end{array} & \begin{array}{c}\text { Incremental cost } \\ \text { Mean }[95 \% \mathrm{Cl}]\end{array} \\ (n=263) & & \end{array}$

(b1) Resource use

Index admission ${ }^{\mathrm{a}}$

Days in critical care

$5.67(6.66)$

$13.93(15.68)$

Days on general medical wards

$12.73(23.94)$

24.31 (34.09)

Total hospital days - index admission

18.40 (26.98)

$38.24(40.37)$

Neuro-surgery ${ }^{* *}, \mathrm{n}(\%)$

$1(0.38)$

$48(8.22)$

$9(3.42)$

$38(6.51)$

$0.31(2.24)$

$0.69(3.98)$

Total hospital days -readmission ${ }^{\mathrm{a}, \mathrm{b}}$

$18.71(27.02)$

$38.94(40.86)$

\section{(b2) Costs}

Index admission ${ }^{\text {a }}$

Critical care costs

General medical costs

Readmission costs ${ }^{\mathrm{a}, \mathrm{b}}$

Outpatient \& community costs ${ }^{b}$

Total costs up to six months ${ }^{\mathrm{a}, \mathrm{b}}$

\begin{tabular}{cc}
$8,347(10,002)$ & $19,632(22,922)$ \\
$3,209(6,022)$ & $6,127(8,582)$ \\
$1,019(3,800)$ & $1,589(5,077)$ \\
$578(1,780)$ & $1,178(2,700)$ \\
$13,153(14,563)$ & $28,525(27,100)$ \\
\hline
\end{tabular}

${ }^{\ddagger}$ Results reported as Mean(SD) unless stated otherwise

*After case mix adjustment

${ }^{* *}$ Intracranial procedure for evacuation of mass lesion

Source: ${ }^{a}$ RAIN Study and CMP Database; ${ }^{b}$ Health Services Questionnaire 
$\mathrm{Cl}$ : confidence interval; SD: standard deviation 
Table 4. Lifetime costs (f), quality-adjusted life years (QALYs), and incremental net monetary benefit (INB)

\begin{tabular}{|c|c|c|c|}
\hline \multicolumn{4}{|c|}{ (a) Comparison 1: dedicated neurocritical care unit versus combined neuro and general critical care unit } \\
\hline & $\begin{array}{c}\text { Combined neuro \& } \\
\text { general critical care unit } \\
(n=1,341)\end{array}$ & $\begin{array}{c}\text { Dedicated neurocritical } \\
\text { care unit } \\
(n=1,324)\end{array}$ & $\begin{array}{c}\text { Incremental effect }{ }^{a} \\
\text { Mean }[95 \% \mathrm{Cl}]\end{array}$ \\
\hline Mean (SD) Lifetime costs & $31,007(22,471)$ & $34,909(26,834)$ & $3,167[-464$ to 6,797$]$ \\
\hline Mean (SD) Lifetime QALYS & $9.49(6.52)$ & $9.99(6.56)$ & $0.224[-0.332$ to 0.780$]$ \\
\hline Lifetime cost per QALY & & & 14,128 \\
\hline INB $^{\mathrm{b}}$ & & & $1,316[-9,857$ to 12,489$]$ \\
\hline
\end{tabular}

(b) Comparison 2: 'early' versus 'no or late' transfer to a neuroscience centre

\begin{tabular}{lccc}
\hline & $\begin{array}{c}\text { 'No or late' transfer to } \\
\text { neuroscience centre } \\
(\mathbf{n = 2 6 3 )}\end{array}$ & $\begin{array}{c}\text { 'Early' transfer to } \\
\text { neuroscience centre } \\
(\mathbf{n = 5 8 4 )}\end{array}$ & $\begin{array}{c}\text { Incremental effect }^{\text {a }} \\
\text { Mean [95\% Cl] }\end{array}$ \\
\hline Mean (SD) Lifetime Costs & $16,105(15,041)$ & $36,422(28,030)$ & $19,209[15,234$ to 23,184] \\
Mean (SD) Lifetime QALYs & $7.19(6.88)$ & $11.55(6.43)$ & $1.795[1.049,2.541]$ \\
Lifetime cost per QALY & & & 10,704 \\
INB $^{b}$ & & & $16,682[2,574$ to 30,791] \\
\hline
\end{tabular}

Cl: confidence interval; SD: standard deviation

a Incremental effects are after case-mix adjustment

${ }^{b}$ INB can be calculated by following methods guidance and multiplying the mean QALY gain (or loss) by $f 20,000$, and subtracting from this the incremental cost 
FIGURES

Figure 1(a).

\section{A: Dedicated neuro unit}

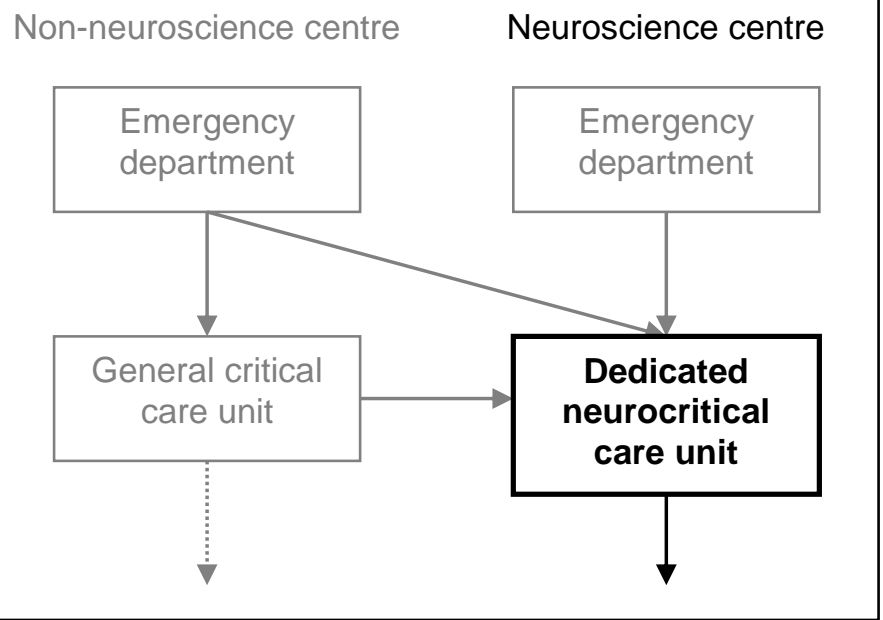

Figure 1(b).

\section{A: Early transfer}

Non-neuroscience centre Neuroscience centre

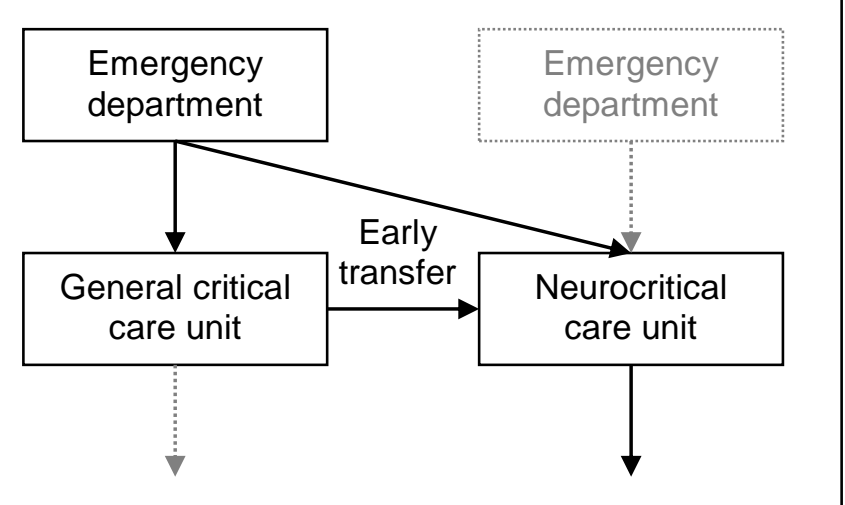

\section{B: Combined neuro/general unit}

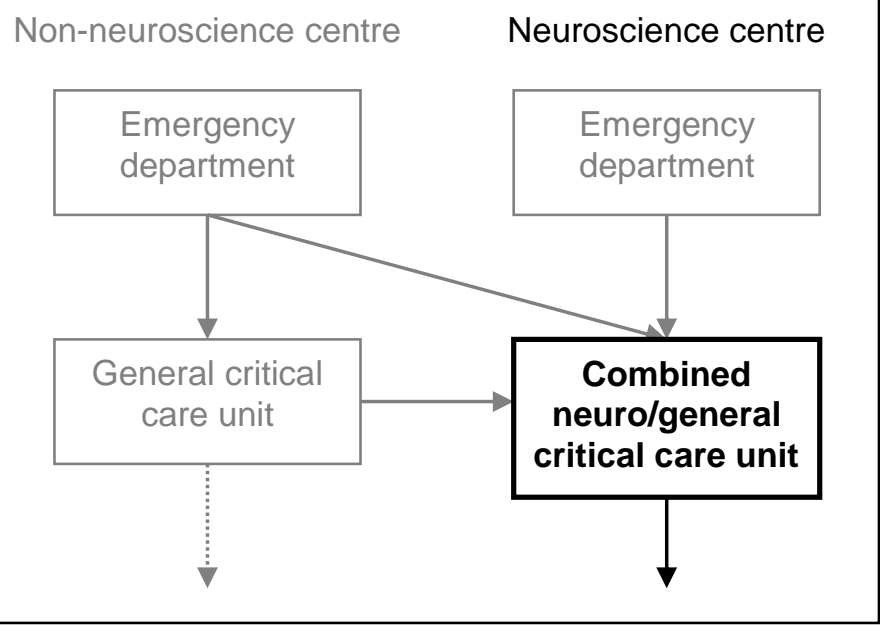

\section{B: No or late transfer}

Non-neuroscience centre Neuroscience centre

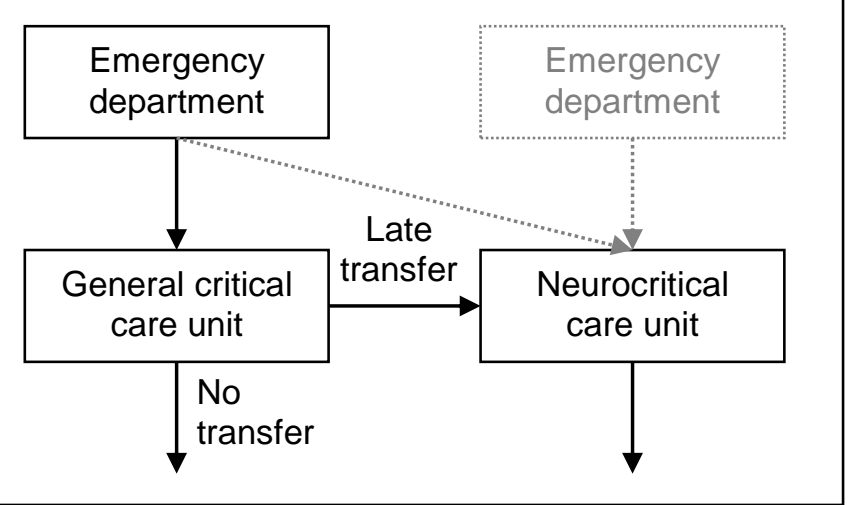


Figure 2(a)

(g) CRASH risk adjustment

(f) Gamma distributed costs

(e) Followup between 150-270 days

(d) Same unit cost across

location of care

(c2) Inpatient cost for 5 years, outpatient

$\&$ community costs upto 10 years

(c1) Inpatient, outpatient \&

community costs upto 5 years

(b) Quality of life weights from RAIN

(a) Gompertz survival

Base case

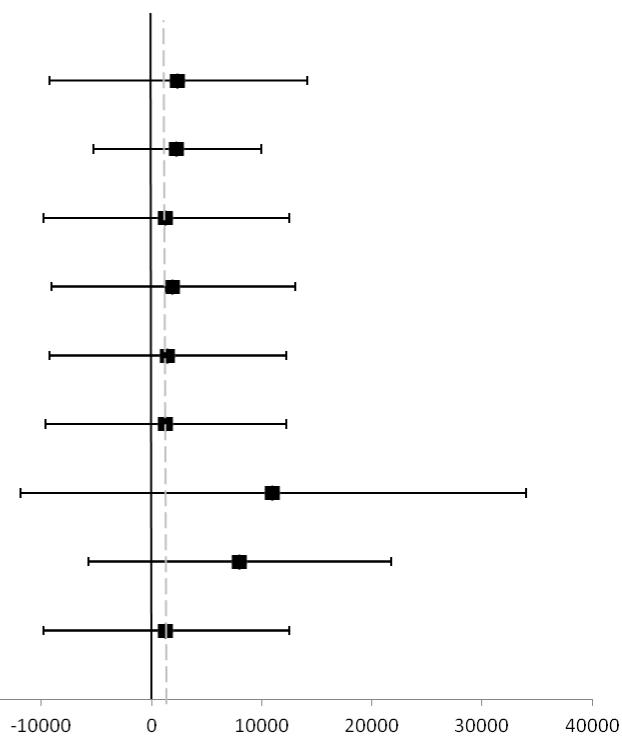

Incremental net benefits at $£ 20,000$ per QALY gain (dedicated neuro versus combined neuro/general)

Vertical dashed line indicates incremental net benefits in the base case analysis. Solid vertical line indicates no difference in net monetary benefits between comparator groups. 
Figure 2(b)

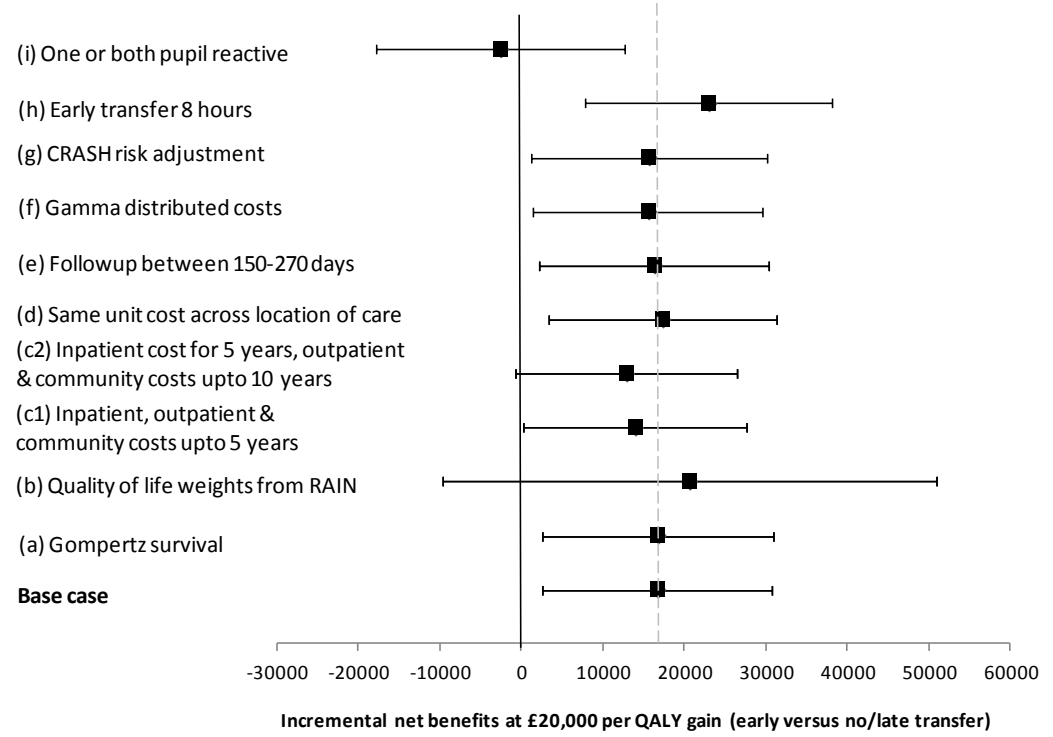

Vertical dashed line indicates incremental net benefits in the base case analysis. Solid vertical line indicates no difference in net monetary benefits between comparator groups. 